\title{
PC-Bang (Room) Culture: A Study of Korean College Students' Private and Public Use of Computers and the Internet
}

\author{
Kym Stewart \\ School of Communication \\ Simon Fraser University \\ Hyewon Park Choi \\ Department of Child Development and Family Welfare \\ University of Ulsan
}

\begin{abstract}
The purpose of this study was to examine how Korean college students use computers within the PC-Bangs as well as at home. Data on media usage and PC-Bang usage patterns was collected from 291 University of Ulsan students. Results suggest that PC-Bangs are used mainly for game playing and have become a male-dominated play space. Female students, however, tended to use computers at home and for other nongaming activities such as chatting and emailing. Data also revealed that displacement of nonmedia-related activities by PC-Bang usage rarely occurred. However, existence of gaming habits did exist and with the abundance of gaming-related activities available in South Korea, these media-related habits may displace similar activities.
\end{abstract}

KEYWORDS NEEDED

\section{INTRODUCTION}

Internet connectedness is thus conceived as a multidimensional indicator of a person's overall relationship to the Internet. Although the concept may add layers of complexity to the traditional notion of media use, the truth is that the role of media in people's lives is more complex than that of electrical appliances. (Logues \& Jung, 2001)

This complexity reaches far beyond the scope of answers given to researchers via surveys or other methodological tools. The living experiences of today's youth is beyond categorization and statistical representation, especially when today's youth

Requests for reprints should be sent to Kym Stewart, School of Communication, 8888 University Drive, Simon Fraser University, Burnaby, British Columbia, Canada V5A 1S6. E-mail: kym@ualberta.net 
are exposed to new media and the world it creates at such a young age where reason and independent thought may be replaced by imitation and mimicking.

A small Korean boy walks into the PC-Bang behind his elder brother and is paralyzed by fear upon confronting a life size Starcraft alien character. Urged by his brother to hurry up and follow, he creeps by the statue and proceeds to the counter with his 1000 won (\$0.75 US) in hand. Though barely able to reach the counter, he carefully places his 1000 won on top for the worker to log him into a computer and proceeds to sit in a king size chair next to his brother. While his sibling prepares the computers for a game of Starcraft the little boy's eyes adjust to the darkness and widen as he examines the Starcraft décor and the sounds of other young children squealing and mocking each other's strategic moves. He pulls himself up to look over his computer to see the row of older boys playing silently and looking intensely at the screen through a cloud of smoke. A nudge from his brother tells him it is time to play and with the rapid clicking of the mouse they are off and running. And so begins the 3 year old boy's initiation into the world of Starcraft and the PC-Bang. (Observation by researcher in July, 2002 at a Korean PC-Bang in Ulsan)

Although South Korea has a thriving entertainment industry it differs from its North American counterpart in that it is not primarily based on home entertainment systems such as home theatre, gaming and console video game systems. Instead the Korean entertainment industry thrives outside of the home in the various "Bangs" provided for the public such as the manwhabang (comic reading room), norebang (singing room), video bang (video viewing rooms), DVD bang (DVD viewing rooms), and more recently the PC-Bangs (PC/ Internet room). This Bang culture has become an integral part of the socializing environment for the Korean population. The introduction of the PC-Bang seemed to be a natural means of providing access to this new media technology. While it seems obvious that the high-performance computers, high-speed Internet connections and low usage fee would make the PC-Bang attractive to users, analysis reveals that the social environment of the PC-Bang is by far the most important factor contributing to its popularity. This paper will examine the popularity of game playing and PC-Bang usage in South Korea among Korean university students.

\subsection{Computerizing the Nation}

South Korea may have been slow to industrialize, but we will lead the world in computerization.

-A 1995 campaign slogan for the Chosun Ilbo newspaper's computer literacy promotion (Akira, 1998)

In an attempt to stimulate the economy and prepare its public for the computer age, the Korean government encouraged a climate that was conducive for mass, inexpensive Internet access. ${ }^{1}$ These governmental campaigns were deemed educationally valuable for Korean society in an attempt "to nurture the future lead-

\footnotetext{
${ }^{1}$ Usual rates for PC-Bang are 1,000 won/hr. 1,000 won is equivalent to approximately US $\$ 1,300$. and $\mathrm{C} \$ 830$.
} 
ers of the 21 century's computerized society" (Akira, 1998). To this end the Korea Information Infrastructure (KII) was established in 1994 to promote nation wide access to affordable telecommunication technologies. The Korean government and the KII stimulated the "competition amongst telecom carriers result[ing] in the establishment of the [Korean] world-class high-speed information \& communication network" that now exists (NCA, 2000c). This first stage of the KII project was achieved in 1997, thus providing "Internet service for 10,000 elementary and secondary schools" and further allowing for "the basic environment needs for providing a digital-orientated education in Korea" to be firmly established (NCA, 2001).

Throughout the United States, some "80,000 schools and libraries" comprise the public access areas for PC usage (Borzekowki \& Rickert, 2001). The Korean government attempted to develop similar community access centers (CACs) as a means of providing public access to its population. However, the Asian economic crisis of 1997 devastated those endeavors and, as Hwang has suggested, in 2000 only 45 Local information centers, 25 Internet plazas (in the local post offices) and 16 public computer education centers existed throughout the country, most of which were under funded and poorly supported (Mun, 2001).

Although public access was part of the KII project plans, IMF and the rising PC-Bang industry within the private sector replaced the necessity for government funded CACs to be developed. The PC-Bang industry provides copious computer and Internet access, even to those who previously did not have the economic means to acquire such technologies, and the PC-Bang has become the second most popular location for computing after the home (NCA, 2001).

Government sponsored programs combined with CACs and PC-Bangs have resulted in wide spread computer access, both at home and within the public sphere. However, the PC penetration in Korea, though extremely high, is unequally divided within economic and geographical realms (Mun, 2001). Not all regions of Korea nor individuals of various economic status levels, have been given equal access, therefore, the digital divide still exists in Korea.

\subsection{Attempt to Close the Digital Divide Gap}

The Act on Closing the Digital Divide was amended in January 2000 and stated

Article 1 (Objective): The objective of the act is to help ensure a universal, unlimited access to the telecommunications networks and use of the telecommunications services for low-income earners, rural residents, the disabled, the aged, women, etc., who have difficulties in accessing or using the telecommunications services for economic, regional, physical or social reasons. So that the nation can improve the quality of living for these people and thereby contribute to the balanced growth of the national economy. (NCA, 2000b)

Governmental endeavors have concentrated on narrowing the divide through a series of projects. The Ministry of Information and Communication (MIC), as part of its digital divide series, proposed the "One PC Per Person" project that entailed the 
government "select[ing] 12 computer companies that could provide low-price [under USD 800] 'civic computers' through the competition consortium" (Mun, 2001).

Therefore, segments of the Korean population, whom may not have had access to the technology prior to the governmental projects, were given access through equalization measures. Borzekowski and Rickert (2001) suggested that "public points of access can serve as an equalizer, providing individuals with Internet connections regardless of income and education." Many deem the governmental projects to close the digital divide via the implementation of computers and the Internet in schools, CACs and the introduction of PC-Bangs as welcomed opportunities for those individuals who do not have access to computer technology. However, further analysis suggests that the "claims of closing these digital divides may be addressing only the most superficial issues of Internet access, thereby masking larger communication technology and inequality issues" (Jung, Qiu, \& Kim, 2001).

Universal and unlimited access to telecommunication may not alleviate the problems of the digital divide in Korea. As Logues \& Jung (2001) stated, the existence of the digital divide may not be the distinction between the "haves and have nots" of the new technology, rather "it is an issue about how central the Internet is or could be in achieving various essential goals in individuals' everyday lives, and how embedded the Internet is in the existing communication infrastructure of older and younger people" (Logue \& Jung, 2001). Therefore, these governmental endeavors to close the digital divide by providing an abundance of access to the new technology may not help in the development of an individual's computer literacy skills, rather it may only add to the number of individuals in the country with access. The Korean computer industry has grown significantly and as a result has contributed to the "growth of the national economy" as the Article 1 objective in the Korean Digital Divide amendment. However, it is very difficult to analyze how this increase in computer access at home and in the public sphere has improved the quality of living for the Korean population when a great deal of time spent on the Internet, especially in the PC-Bangs, is spent gaming and chatting online.

\subsection{Gender}

Recent Internet research shows a narrowing in the gender divide of Korean Internet users, in which $45.2 \%$ of women and $54.8 \%$ of men use the Internet (NetValue Korea, 2001). However, surveys conducted with PC-Bang owners have suggested that female computer users make up less than $10 \%$ of their clientele. Observations have also shown that very few women seem to be using the Internet at the PC-Bangs, thus it may be inferred that the women are accessing the new media from their home environment. Studies on Korean female Internet users have indicated that "females tend to use the Internet for community activities such as E-mail, chatting, and shopping much more than males do "(NCA, 2001). Hwang (1999) confirmed the notion that women use the Internet for activities such as chatting while "males use it for gaming" (Choi \& Haque, 2002). Because these community activities do not require the computer processing nor Internet speed that many gaming activities do, gender preferences of computer related activities would contribute to the gender inequali- 
ties in Korean PC-Bangs. Furthermore, recent PC-Bang surveys suggested that, "over half of all Korean Netizens (56.8\%) are using games and a quarter (25.4\%) are using instant messaging" (NetValue Korea, 2001).

Since the inception of an electronic gaming culture, a gender divide in North America has been commonly witnessed. Wright et al. (2001) suggested much research has focused on the patterns of "boys using the computer more than girls do, particularly to play video games and computer games." Korea, however, may be an exception to this tendency. Governmental policies and bans on Japanese imports, including video games and video game consoles, have resulted in very few children having access to these games. Although these video games and consoles were available on the black market, parents generally did not approve of their children wasting time with these "frivolous toys" (Park, 2001). Computers however, were deemed educational and thus a welcomed addition to the home mediated environment, causing Korea's gaming industry to be based on a "large PC market and a small console market" (Park, 2001).

\subsection{Displacement and Addiction}

With computer and Internet access so readily available to the public, both at home and at the PC-Bangs, the notion of Internet addiction and displacement of other media and nonmedia activities comes into question. The Annenberg Public Policy Center's research on "Television in the Home" concluded that participants with computers in their homes watch slightly less television per day, therefore, new media may replace old media (Subrahmanyam et al., 2001). Other research projects however, have concluded that the merging of old and new technologies will allow for two or more media to be used simultaneously. Media Metrix (1999) suggested that $49 \%$ of households with TV and computers use this media in such a simultaneous manner (Subrahmanyam et al., 2001). Kraut and associates (1998) suggested that media may displace nonmediated activities and their studies indicated that online media has disrupted communication between family members (Kayant \& Yelsma, 2000). Whether the new media displaces old media or nonmedia-related activities, the results suggest that the daily lives of children in the 21st century are mediated and will continue to be so, especially in Korea where the need to lead the world in computerization promotes an abundance of new media technology. The PC-Bang provides a unique element in the debate of media displacement and multiple media usage patterns. Unlike the home environments, where various media are present for consumption, the PC-Bang provides a nearly pure PC computing environment, minus the private cell phones brought in by its users. Thus the exploration of the PC-Bang environment becomes important as a comparison of computer usage patterns at home and in a pure PC mediated environment. It also vital to further understand how the youth has incorporated the PC-Bang into their daily lives and what role the PC-Bang plays in the peer relations of the Korean youth.

\footnotetext{
${ }^{2}$ Recent focus group participants explained the increase of Korean students' computer game playing using this creed.
} 
Among the Korean youth, a creed to succession in the computer world lies in the saying, "If you want to learn to use a computer, (you) need to be addicted to Chatting rooms and Computer games" (Lee, 1996). ${ }^{2}$ The Korean Herald (2000) reported that " $50.3 \%$ percent of respondents said their day-to-day life was most influenced by Internet-based communications", therefore it may be inferred that an increasingly "rapid shift from human communications to Web-based communications in Korea" may be cause for alarm (Korean Herald, 2000). Korean addiction centers have now expanded and new treatment centers have been added to deal solely with Internet addiction. Examination of Internet users by the Commission on Youth Protection found that "11 percent of elementary to high school students have a potential to become seriously addicted to the Net" (Shin, 2000). Prior surveys suggested that $44.1 \%$ of elementary and middle school PC users "reported some experience of computer addiction" (Lee, 1996). Tendency for younger computer users to become addicted is a serious issue that affects both the child and the family. Research on the younger generation of Internet users has suggested that they may develop a more serious addiction than that of adults, and some reports have suggested that, "some young Internet addicts leave home when they are banned by their parents from using the computer" (Shin, 2000). The young generation may often encounter peer pressure related to knowledge and skill level of gaming activities. These pressures and the trend of gaming are also encouraged in the public sector with sponsorship and much attention given to pro-gamers and gaming competitions in Korea. The gaming competitions and emphasis on becoming an expert player may cause addiction or displacement problems when the Korean gaming public has $24 \mathrm{hr}$ access to an unmediated PC environment. Therefore the role of peers becomes an important element when viewing the usage patterns of students using the PC-Bangs.

\subsection{Competition}

Exposure given to pro-gamers and the gaming industry seems to have had a profound effect on the youth culture of today in South Korea. Pro-gamers in Korea are given a great deal of media exposure and their achievements are greatly revered by much of the gaming youth. Game competitions at some PC-Bangs are weekly events and three television stations are dedicated to gaming events within Korea. With the incredible popularity of gaming in Korea it may be assumed that Korea provides a vast market for the video game industry. Yet ethnographic and statistical analysis of the gaming community has shown that not only do Korean gamers prefer one type of platform, the PC, but their game selection is limited as well. A relatively small number of games are played and enjoyed throughout Korea. Starcraft, Diablo, Fortress, Fifa and Lineage seem to be the most popular games. The most popular game seems to be the Starcraft expansion set Brood Wars that was released in 1998. In few other countries would a game become so popular and maintain that popularity for over 4 years. Our study questioned gamers about the popularity of Starcraft in Korea and many have stated that they started to play because their friends played and they did not want to be left out. Chung (1996) suggested that 
Korea has been described as on of the most collectivistic cultures. People in collectivistic cultures live in strong and cohesive ingroups and value ingroup solidarity, harmony, and duties. Ingroup norms are strictly followed making the members reluctant to stand out.

The need to fit in and become a member of the in-group seems to be a strong driving force behind the gaming phenomenon in Korea. With the introduction of PC-Bangs to Korean society came the introduction of Starcraft. This simultaneous introduction of increased access to computers and Starcraft, combined with the strong competitive nature of the Korean population, has promoted the popularity of Starcraft to the present day. Its popularity is reinforced by the existence of numerous pro-gamers and corporate competitions. The strong competitive culture has promoted the continuation of game popularity as well as the PC-Bang culture.

\section{METHOD}

This study is the first in a series aimed to promote a further understanding of the PC-Bang environment. This study, however, only deals with media and PC-Bang usage of students from the University of Ulsan. Preliminary studies of PC-Bang memberships concluded that of 1,346 registered members 1,319 were men and 20 were women. It was also seen that of the 1,346 members 1,085 were university students. This initial investigation lead to the development of a survey geared towards university students because they seemed to most often frequent the PC-Bang and, due to of their age and educational status, did not have strong parental mediation patterns to prevent them from spending a great deal of time at the PC-Bang.

The survey questioned the students' access to media both within their homes and in their bedrooms. It also asked, using the 5-point Likert scale, their preference for a variety of media and nonmedia-related activities. A time chart of gaming activities in various environments was completed by the students as well as an account of their PC-Bang usage, including how often and with whom they most often go to the PC-Bang. Finally, questions regarding their opinions of media displacement and media addiction were asked. Due to the cross cultural nature of the research project, special care and attention was needed to ensure a non-Korean bias was not present. Therefore focus groups were used to develop the questions and choices of answers to be used in the PC-Bang survey. Once a better understanding of the survey form, which is commonly used in Korea, was obtained the survey was translated from English to Korean. A series of pretest were used to ensure that both the content and structure was deemed appropriate for Korean university students.

\subsection{Sample}

Undergraduate students at the University of Ulsan completed a total of 291 surveys, 67 of the surveys were from the pilot and the other 224 from the study. The final demographics indicate that the sample had 158 male students and 133 female students. The average age of the male students was 24 to 26 years of age and the female 
students were 20 to 22 years of age. Due to the mandatory army service duty in Korea, the men, on average, are 2 years older than the female students in the same year of study.

\subsection{Instruments}

The survey comprised 14 closed-ended questions and 2 open-ended questions, the first open-ended question asked why the students went to the PC-Bangs and the other was an optional question asking for the students input on the survey or additional information about PC-Bangs.

\subsection{Procedure}

The surveys were administered during the fall semester of 2001 to class of Liberal Arts and engineering students. All except 100 surveys were given to the students in class, and the 100 that were not were handed out and returned during the next class that had a lapse of 1 week. Student participants ranged from freshman to seniors. Once the surveys were collected they were coded and statistically analyzed using Data Mining Software by SPSS.

\section{RESULTS}

\subsection{Descriptive Analyses}

The majority of students' families incomes ranged from 10 million Korean Won to 30 million Won per year ( $\$ 9,000$ to $\$ 23,000$ American per year). Living styles did not show much gender variance. The results indicated that $41.7 \%$ of the male students and $53.9 \%$ of the female students lived in apartments, followed by those who lived in houses, $35.3 \%$ of males and $35.2 \%$ of females. $61.7 \%$ of the male students stated they lived with their parents. The second most common answer was dormitory residents at $18.8 \% .80 .4 \%$ of the female students stated they lived with their parents, and like the male students, dormitory residents at $9.3 \%$ was the second most common choice.

\subsection{Access to the Media}

Internet usage by women has increased much more than men in Korea and, as Table 1 suggests, the access to media in the home does not show any significant gender differences.

\subsection{Time Spent With Media at Home and at PC-Bang}

Of the students, $42.4 \%$ of the males and $21.7 \%$ of females estimated that they go to the PC-Bang 1 to 2 times per week. Male students spent more time in gaming activi- 
Table 1

Percentage of Access to Media in the Home and in the Bedroom

\begin{tabular}{|c|c|c|c|c|c|c|}
\hline & \multicolumn{3}{|c|}{ Home } & \multicolumn{3}{|c|}{ Bedroom } \\
\hline & Men & Women & $t$ & Men & Women & $t$ \\
\hline Computer & 92.4 & 95.4 & 1.054 & 83.5 & 58.5 & $-4.91^{* *}$ \\
\hline Internet & 76.6 & 78.5 & 0.378 & 69.6 & 45.4 & $-3.90^{* *}$ \\
\hline High speed & 95.0 & 86.3 & $2.299 *$ & 63.3 & 40.8 & $-4.27^{* *}$ \\
\hline Television & & & & 62.0 & 30.5 & $-5.60^{* *}$ \\
\hline VCR & & & & 50.0 & 15.3 & $-6.63^{* *}$ \\
\hline Video games & & & & 6.3 & 3.8 & -0.94 \\
\hline
\end{tabular}

${ }^{*} p<.05 .{ }^{* *} p<.01$.

Table 2

Hours Spent Gaming Per Week in Various Gaming Environments

\begin{tabular}{|c|c|c|c|c|c|c|c|c|}
\hline & \multicolumn{3}{|c|}{ Men } & \multicolumn{3}{|c|}{ Women } & \multirow[b]{2}{*}{$t$} & \multirow[b]{2}{*}{$p$} \\
\hline & $N$ & $M$ & $S D$ & $N$ & $M$ & $S D$ & & \\
\hline Time spent playing online games at home & 141 & 3.31 & 5.24 & 108 & 1.46 & 4.11 & 2.53 & .01 \\
\hline $\begin{array}{l}\text { Time spent playing computer games at } \\
\text { home }\end{array}$ & 142 & 2.49 & 4.16 & 108 & 1.47 & 2.81 & 2.19 & .03 \\
\hline $\begin{array}{l}\text { Time spent playing video games at home } \\
\text { Time spend playing online games at }\end{array}$ & 141 & 0.19 & 0.93 & 108 & 0.17 & 0.88 & 0.65 & .51 \\
\hline PC-Bang & 141 & 2.83 & 7.99 & 108 & 0.48 & 1.44 & 5.06 & .00 \\
\hline $\begin{array}{l}\text { Time spent playing computer games at } \\
\text { PC-Bang }\end{array}$ & 142 & 2,17 & 799 & 108 & 0.36 & 247 & 228 & 02 \\
\hline Time spent playing games at arcade & 141 & 1.31 & 3.79 & 108 & 0.56 & 1.11 & 1.99 & .05 \\
\hline Time spent playing games on cell phone & 141 & 0.04 & 0.25 & 108 & 0.19 & 0.93 & -1.83 & .07 \\
\hline
\end{tabular}

ties than female students in all mediated environments questioned as shown in Table 2. Online gaming in the PC-Bangs was one activity where a dramatic difference in time usage was seen between male and female students. Female students were asked to comment on why they did not go to the PC-Bangs and many complained about the unhealthy environmental conditions due to smoking in the PC-Bangs and the lack of nongaming programs in the PC-Bangs as reasons for staying at home and using their own computer or the computer at school.

\subsection{PC-Bang Accompaniment}

Friends seem to be the number one choice of students as an accompanying PC-Bang user, $80.9 \%$ of male and $62.8 \%$ of female students selected friends and only $12.1 \%$ of male and $24.0 \%$ of female students said they often go to the PC-Bang alone. Focus groups and interviews with gamers and non-gamers have helped to enlighten the notion of the PC-Bang as a socialization facility in the lives of the Korean youth today. Many students have suggested that the PC-Bang provides a stress free, fun and youth dominated environment where groups of friends can meet and engage in a 
cooperative game. They have suggested that the games themselves may promote a social environment by promoting the development of squads or groups of players to play the game more effectively.

3.4.1 Activity Preferences at PC-Bang. Results of Table 3 seem to suggest that the female students enjoyed a variety of activities at the PC-Bang, whereas the male students seem to enjoy playing online games the most, which is consistent with previous PC-Bang and Korean computer use research findings (Hwang as cited in Choi \& Haque, 2002).

3.4.2 Genres. There were significant gender differences in the preferences of computer and online game genres most often present at Korean PC-Bangs as shown in Table 4. Female students enjoyed more skill related games such as Tetris and online card games. The male students, however, enjoyed multiplayer games that seem to correlate with the finding of males going to the PC-Bang with other friends because multiplayer games may lend themselves to a more social arena of playing.

\subsection{Displacement}

The survey asked the students to estimate how often certain events were displaced while they were at the PC-Bang. The list included displacement of sleep, school, homework, promises to meet with friends and time spent with friends. Results indicated that sleep was the only activity sometimes missed because of PC bang usage, where $46.3 \%$ of the male and $23.1 \%$ of the female students sometimes went to bed late. Also, $3.7 \%$ of the male and $3.8 \%$ of the female students said they always went to sleep late. The second most missed activity was homework with $15.5 \%$ of male and $3.7 \%$ of female students not doing their homework because of their PC-Bang usage.

When asked at what time of day the students went to PC-Bangs, the results indicated that $44.9 \%$ of the male students went to the PC-Bang late at night and $19.6 \%$ went in the evening. The indication of displacement of sleep may have re-

Table 3

Activities at the PC-Bang

\begin{tabular}{|c|c|c|c|c|c|c|}
\hline \multirow[b]{2}{*}{ PC-Bang Activity } & \multicolumn{2}{|c|}{ Men } & \multicolumn{2}{|c|}{ Women } & \multirow[b]{2}{*}{$t$} & \multirow[b]{2}{*}{$p$} \\
\hline & $M$ & $S D$ & $M$ & $S D$ & & \\
\hline Like to email & 2.09 & .78 & 1.72 & .67 & 4.15 & .00 \\
\hline Like to chat & 2.70 & .85 & 2.41 & .72 & 2.57 & .01 \\
\hline Like to look at Web sites & 2.42 & .72 & 1.94 & .67 & 5.39 & .00 \\
\hline Like to play online games & 2.00 & .93 & 2.44 & .93 & -3.39 & .01 \\
\hline Like to use for school work & 2.55 & .77 & 2.38 & .73 & 1.82 & .07 \\
\hline Like to use multimedia options & 2.82 & .73 & 2.38 & .77 & 4.45 & .00 \\
\hline Like to download music & 2.43 & .86 & 1.85 & .72 & 5.46 & .00 \\
\hline Like to shop online & 2.82 & .90 & 2.33 & .86 & 4.03 & .00 \\
\hline Like to surf Internet for no real purpose & 2.75 & .77 & 2.60 & .89 & 1.22 & .23 \\
\hline
\end{tabular}

Note. Based on a 4-point Likert scale ranging from 1 (really like to) to 4 (don't really like). 
Table 4

Gender Differences in Gaming Genres Present at PC-Bangs

\begin{tabular}{|c|c|c|c|c|c|c|c|c|}
\hline \multirow[b]{2}{*}{ Genre } & \multicolumn{3}{|c|}{ Men } & \multicolumn{3}{|c|}{ Women } & \multirow[b]{2}{*}{$t$} & \multirow[b]{2}{*}{$p$} \\
\hline & $N$ & $M$ & $S D$ & $N$ & $M$ & $S D$ & & \\
\hline First person shooter (Rainbow 6) & 127 & 2.31 & .92 & 71 & 2.86 & .92 & -3.99 & .00 \\
\hline Multiplayer (Fortress) & 139 & 1.92 & .89 & 88 & 2.28 & .88 & -2.99 & .003 \\
\hline Skill (Tetris) & 133 & 2.30 & .82 & 119 & 1.86 & .63 & 4.79 & .00 \\
\hline Sports (Fifa soccer) & 130 & 2.28 & .97 & 58 & 3.24 & .68 & -6.87 & .00 \\
\hline
\end{tabular}

Note. Based on a 4-point Likert scale ranging from 1 (really like to) to 4 (don't really like).

sulted from approximately $45 \%$ of the male students using the PC-Bang late in the night. Whereas $28.1 \%$ of the female students indicated that they went in the afternoon and $28.1 \%$ of the female students stated they went in the evening. Prior to the World Cyber games in Seoul in December 2001 there were game championships being played throughout Korea. The Korean Herald reported on one such event stating "400 gamers yesterday finished their 'sleepless' two-day non-stop event" the event attracted not only 400 players but 2000 spectators (Yang, 2001a). Sleepless nights seem quite common because the PC-Bang is open $24 \mathrm{hr}$ and provides users special rates if they play from midnight until 8 am in the morning. One student surveyed suggested that because the PC-Bangs are open $24 \mathrm{hr}$, than people will go and stay for $24 \mathrm{hr}$.

\subsection{Correlational Analyses of Game Use}

There was significant correlation among the use of games in different gaming environments, such as at home and elsewhere like the PC-Bang or the arcade (see Table 5). If participants (males and females) played more computer games at home, they played more video games at home $r=.271, p<.00$ ). If the participant (male and female) played more computer games at home they spend more time at the PC-Bang playing online games $r=.217, p<.001$ ). If the participant (male and female) played more computer games at home, then they would spend more time playing at the arcade $r=.440, p<.000$ ). If the participant (male and female) played more computer games at home then they would spend more time playing cell phone games $r=.179, p<.004$ ). If the participant (male and female) played more computer games at home, then they would spend more time playing online games at home $r=.423, p<.000)$.

Other correlation results worth mentioning were those between "video game use at home," "cell phone," and "other electronic game use." If participants (male and female) spent time playing video games at home, then they spend more time playing cell phone games $r=.705, p<.000)$ ). If participants (male and female) spent time playing video games at home, then they spent more time playing other electronic games $r=.757, p<.000$ ).

Analyses of time spent playing computer games at the PC-Bang revealed some consistent difference between male and female students. Time spent using the 
Table 5

Time Spent Gaming at Home Correlated With Time Spent Gaming Elsewhere

\begin{tabular}{|c|c|c|c|c|c|c|}
\hline \multirow[b]{2}{*}{ Time Spent ... } & \multicolumn{3}{|c|}{$\begin{array}{l}\text { Time Spent Using Computer } \\
\text { at Home for Computer Games }\end{array}$} & \multicolumn{3}{|c|}{$\begin{array}{l}\text { Time Spent Using Computer at } \\
\text { PC-Bang for Computer Games }\end{array}$} \\
\hline & & $r$ & $p$ & & $r$ & $p$ \\
\hline \multirow[t]{3}{*}{ Playing online games at PC-Bang } & Men & .193 & .002 & Men & .318 & .000 \\
\hline & Women & .105 & .281 & Women & .179 & .064 \\
\hline & Total & .217 & .001 & Total & .340 & .000 \\
\hline \multirow[t]{3}{*}{ Using online games at home } & Men & .517 & .000 & Men & -.072 & .398 \\
\hline & Women & .130 & .179 & Women & .057 & .561 \\
\hline & Total & .423 & .000 & Total & -.018 & .776 \\
\hline \multirow[t]{3}{*}{ Playing cell phone games } & Men & -.015 & .861 & Men & -.024 & .776 \\
\hline & Women & .315 & .001 & Women & .301 & .002 \\
\hline & Total & .179 & .004 & Total & .088 & .164 \\
\hline \multirow[t]{3}{*}{ Playing video games at home } & Men & .242 & .004 & Men & -.020 & .817 \\
\hline & Women & .253 & .008 & Women & .336 & .000 \\
\hline & Total & .271 & .001 & Total & .080 & .207 \\
\hline \multirow[t]{3}{*}{ At the arcade } & Men & .437 & .000 & Men & -.022 & .793 \\
\hline & Women & .439 & .000 & Women & .468 & .000 \\
\hline & Total & .440 & .000 & Total & .040 & .530 \\
\hline
\end{tabular}

computer at the PC-Bang for female students was strongly correlated to their cell phone game usage $r=.301, p<.002$ ), video game playing at home $r=.336, p<.001$ ) and arcade game playing $r=.468, p<.000)$.

\section{DISCUSSION}

The implementation of thousands of PC-Bangs throughout Korea seemingly granted equal access to computers with high speed Internet connections for individuals who did not own a personal computer or have access to high speed Internet. Our research, however, has indicated that male students, even though they have access to the media in their homes and in their bedrooms, make up the majority of PC-Bang users. Our data and participatory observation has confirmed that the PC-Bangs have now become a male-dominated gaming environment. Benenson et al.'s (2001) description of adolescent behavioral patterns suggested that men interact in larger groups more often than women do. They also suggested that men may often engage in a more competitive display of behaviors as part of the play activities. Our study seems to confirm this theory when examining PC-Bang behavior. The male students who often go to the PC-Bang may engage in online or computer game competition with their friends, thus it may be inferred that the environment appeals to the male students not only due to the plethora of gaming options but also because the PC-Bang environment lends itself to a competitive and social arena. The competitive and social characteristics displayed in the PC-Bang are also important and relevant elements of Korean society, thus the act of gaming, which has quickly gained popularity in Korea, combined with the competitive and social nature of the Korean gaming community may help maintain gaming as a popular form of entertainment. 
Shanahan and Flaherty (2001) also suggested that adolescents have a limited domain of behaviors that they enjoy, which is conclusively found in our study of the gaming culture and computer users at the PC-Bangs. If the male students enjoy one method of gaming, such as arcade games, they often enjoy other gaming activities such as computer games at home or online games at the PC-Bang. These activities may promote "feelings of esteem, efficacy, authenticity, and engagement" that has been seen by some psychologists to promote the individual to seek out related activities as a means of fulfilling their habit (Shanahan \& Flaherty, 2001). Psychologists have often stated that an individual's engagements of similar activities are the result of an individual experiencing. Therefore, the men who engage in gaming activities at home may automatically be drawn to the potential of gaming away from home, either at the PC-Bang or the arcade, due to positive experiences of past gaming.

With $90 \%$ of PC-Bang revenue obtained directly from gaming, the clientele and their preferences of activities are clearly defined to the PC-Bang owner, and the owner in return may provide more gaming activities for the users (Yeung, 2001). Therefore, the catering to the gaming culture by the PC-Bang industry once again widens the digital divide. The women's choices of PC related activities, such as email and chatting do not necessarily need high speed Internet and a fast processing speed, unlike the gaming activities. Therefore it may be inferred that the environmental conditions of the PC-Bang, such as lack of nongaming programs and lack of a conducive environment for chatting or emailing may cause female users to remain at home or find alterative means of computing. Governmental policies to help decrease the gender divide and allow an arena of public computers has quickly been taken over by the private sector. Thus the private sector, whose primary concern is economic not social welfare, may not accommodate for nongaming or noncomputer literate patrons. The government, however, has made little attempt to continue their pursuit of equal access, rather their attention, much like the private sector has turned to gaming with the development of a Korean Game Promotion Center and the Ministry of Culture and Tourism along with Samsung supporting events such as the World Cyber Games (Yang, 2001b). An analysis of the genre of preferences for both male and female students indicated that the male students often preferred the games that involved multplayers, while female students' preferences seemed to be games requiring skill and that were often played in a single player mode, which did not require her to go to a PC-Bang if computer access was granted at home. If a female student did want to play games at the PC-Bang, her game choices were often limited to the genres of sports, first person shooter, strategy and massively multiplayer games. Research on computer mediated communication has suggested that the Internet is a male domain and to maintain this

predominantly male domain, women are often harassed and intimidated to either leave or comply with the rules of the setting. As in other traditionally male-dominated domains, females are often ridiculed or intimidated within this male-dominated context. (Soukup, 1999)

The need to comply with the rules of the setting may create an undesirable atmosphere for the females at the PC-Bang. Focus group and interviews indicated that 
many women disliked the smoke filled atmosphere and the dirty and dark conditions of some PC-Bangs, therefore they may prefer to use the computer at home or at school. Whereas the male students because of their preference for peer group play seem to be forced, by lack of copious home space, to play at the PC-Bang. Not only do many students lack home space that prevents groups of friends from engaging in a gaming activity at home, but if they do live with their parents, Korean culture does not often encourage groups of children into the home to play. These factors, combined with limited game genre preferences, may add to the maintenance of the PC-Bang as a male dominated environment

\subsection{Displacement}

Our study suggests that displacement of other nonmedia-related activities rarely happens in students' lives. Therefore, students indicated that they rarely miss a meeting with friends or miss time with their families while spending time at the PC-Bang. Himmelweit, Oppenheim and Vince (1958) suggested that at the onset of a new medium the medium most often displaced "are those serving the same functions or offering the same gratifications as the new medium" (Kayany \& Yelsma, 2000). We may, however be able to assume that similar activities may displace other similar activities, thus gaming at home may displace gaming at the PC-Bang. Many students have suggested that the PC-Bang displaced the billiard rooms or pool halls that were most frequented by male students prior to the PC-Bang phenomenon. Due to the quick industrialization and computerization of Korean society, the displacement patterns may differ from those of other countries and careful examination of cultural and historical elements in the development of the PC-Bangs need to be taken into consideration. Once a better understanding is reached regarding the realms of activities that students enjoy, the issue of displacement may become more fully understood. However, due to the merging of technologies and variations in mediated environments it also will become more complicated.

Home media access, and particularly bedroom media access, has often raised the notion that the users engage in a media alone, thus decreasing face-to-face communication with friends or family. However, as Etzioni and Etzioni (1999) stated, face-to-face communication is not guaranteed when participants' experiences are within the same environment. Observation within the PC-Bang has shown this phenomenon on various occasions. A group of male users or a group of female users will enter the PC-Bang and sit for hours without saying a word to one another. Although on occasion a group of gamers will enter the PC-Bang and engage in heckles and shouting at each other while playing a multiplayer game, the majority of the time players are fully engaged in their own game play. Our study indicated that over half of the PC-Bang users stated that they went to the PC-Bang with friends, therefore it may be misleading to infer that these friends engage in much face-to-face communication during their period of stay in the PC-Bang. Choi (2001) suggested that Korean university students' Internet usage "negatively affected their use of other media and face to face communication". Further analysis of the users' personal definition of $\mathrm{f} 2 \mathrm{f}$ communication with friends while in the PC-Bang 
will promote an understanding of whether or not they find this activity to be an interactive play activity or a parallel play activity.

\section{CONCLUSIONS}

The popularity of Korean gaming culture and the PC-Bang gaming environment is the focus of this study. This study revealed tendencies of certain students to gravitate towards the PC-Bang as a means of entertainment and social interaction, but the results have also raised a number of questions regarding the social implications of the PC-Bang culture. South Korea has developed a thriving computer industry with the Internet use reaching over $50 \%$ of the population, currently 25 million citizens, using the Internet, and 14.4 million Korean homes are equipped with Internet access (KRNIC, 2002, Yang, 2002). Accompanying this high rate of home Internet access is the estimated 25,000 PC-Bangs that now exist (Lee, 2001). Although the PC-Bang industry did not start until 1998, it has quickly became a thriving business, creating it's own PC-Bang culture, a culture that is currently defined by the popularity of computer game playing among the youth.

The extensive availability of Internet access throughout Korea, both at home and in various public locations such as bus stations, airports, post offices, restaurants, beauty salons, and the numerous PC-Bangs, has helped to provide an abundance of computer access in Korea. Conveniently located computers provide inexpensive access to the Internet, promoting a freedom to explore that is unlike that of other connected countries.

This research has helped to further understand the role of the PC-Bang in the lives of the Korean youth today. Yet the implications of copious amount of time spent at the PC-Bang gaming and the intense need to compete causes increased concern about addiction and displacement problems of the Korean PC-Bang users. Continued research is needed to assess the media habits that may have formed with the introduction of the new media and the PC-Bang media environment. The current gaming environments at the PC-Bangs have been changing through out the past year. Recent studies have suggested that PC-Bang usage has decreased by $6.1 \%$ (NCA, 2001). However the PC-Bang still seems to be a lucrative business and recently owners have developed new means of attracting customers, such as redecorating, couple centers and cleaner brighter atmospheres. Further data needs to be collected as to which segments of the Korean population use computers, what access points and for what purpose, to provide a broader understanding of the computing environment in Korea. This study has provided a broad picture of the PC-Bang environment, further analysis of individual students, based on the genre of the games, specific games, and time spent gaming may allude to the distinction between the social gamer and the hard-core gamer. To fully understand the gaming culture the individual gamer and nongamers need to be fully understood.

The PC-Bang industry is said to be "a promising industry which is expected to be a 1.3 trillion won market" (NCA, 2001). The gaming industry and computer industry is not only a market within the private sector but is promoted by govern- 


\section{STEWART AND CHOI}

mental initiatives. The amount of money within the gaming industry will support the continuation of the gaming culture in Korea, therefore it becomes important to view these changes and examine their effects on Korean society and particularly the younger generations.

-PC bangs are as addictive as a narcotic. (University of Ulsan male student)

\section{REFERENCES}

Akira, S. (1998). The effects of recession on computer education from the book and the computer; the future of the printed word. Retrieved October 10, 2001, from www.honco.net/archives/980806.html

Benenson, J. F., Nicholson, C., Waite, A., Roy, R., \& Simpson, A. (2001). The influence of group size on children's competitive behavior. Child Development, 72, 921-928.

Borzekowski, D. L. G., \& Rickert, V. I. (2001). Adolescents, the Internet, and health issues of access and content. Applied Developmental Psychology, 22, 49-59.

Choi, Y. J. (2001, June). Investigating Korean college ztudents' Internet use patterns and motivations, and exploring vulnerability of Internet dependency. Paper presented at AEJMC, in Washington, DC.

Etzioni, A., \& Etzioni, O. (1999). Face-to-face and computer-mediated communities, a comparative analysis. The Information Society, 15, 241-248.

Greenfield, P. M. (1984). Mind and media; the effects of television, video games, and computers. In J. Bruner, M. Cole, \& B. Lloyd (Eds.), The developing child. Cambridge, MA: Harvard University Press.

Jung, J., Qiu, J. L., \& Kim, Y. (2001). Internet connectedness and inequality: Beyond the "divide.". Communication Research, 28, 507-535.

Kayany, J. M., \& Yelsma, P. (2000). Displacement effects of online media in the socio-technical contexts of households. Journal of Broadcasting E Electronic Media, 44, 215-229.

Korean Network Information Center. (2002). Number of Internet users in Korea (by year). Retrieved July 13, 2002, from http:/ / stat.nic.or.kr/english/iuser.html

Lee, C. J. (1996, June). Interpersonal relationships in multimedia society: A life-span perspective. Paper presented at the 50th anniversary conference of the KPA, Seoul, Korea.

Lee, J. (2001, October 2). PC rooms boost sales of virtual CD-ROM drives developed by Space International. Korean Herald Infotech section. Retrieved October 10, 2001, from www.koreaherald.co.kr/SITE.data/ html_dir/2001/10/06/200110060028.asp

Logues, W. E., \& Jung, J. (2001). Exploring the digital divide; Internet connectedness and age. Communication Research, 28, 536-562.

Mun, S. H. (2001). Internet access of youth in South Korea: A case study of the PC room. Paper presented at the International Communication Association Conference, Washington, DC.

NCA. (2000a). 1Pv6 and 6NGIX. Retrieved January 1, 2002, from www.nca.or.kr/main/e_nca.main.htm

NCA. (2000b). Act on closing the digital divide. Retrieved January 1, 2002, from www.nca.or.kr/main/ e_nca.main.htm

NCA. (2000c). Establishment of basic plan for KII upgrade. Retrieved Jaunuary 1, 2002, from www.nca. or.kr/main/e_nca.main.htm

NCA. (2001). Korea Internet white paper. Retrieved January 10, 2002, from www.mic.go.kr/eng/ jsp/res/res_300_02.jsp

Neemann, J., \& Harter, S. (1986). Manual for the Self-Perception Profile for College Students. Denver, CO: University of Denver.

NetValue Korea. (2001, February 20). Korean Internet behavior survey. Retrieved October 10, 2001, from http:/ / www.kr.netvalue.com/presse/cp0013/htm

Park, B. H. (2001). How to market to Korea: Small country, large market for PC games. Paper presented at the Game Developers Conference, San Jose, CA. Retrieved February 6, 2002, from www.gdconf.com/archives/ proceedings/2001/park.doc

Shanahan, M. J., \& Flaherty, B. P. (2001). Dynamic pattern of time use in adolescence. Child Development72, 385-401 
Shin, K. (2000). Internet addiction taking toll on families. The Korean Herald. Retrieved October 9, 2001, from www.koreanherald.co.kr/SITE/data/html_dir/2000/11/11/20001111003

Soukup, C. (1999). The gendered interactional patterns of computer-mediated chatrooms: A critical ethnographic study. The Information Society, 15, 169-176

Subrahmanyam, K., Greenfield, P. M., Kraut, R., \& Gross, E. (2001). The impact of computer use on children's and adolescents' development. Applied Developmental Psychology, 22, 385-401.

Survey finds netizens' daily life swayed most by Internet. (2000, September 6). Korean Herald. Retrieved October 10, 2001, from www.koreaherald.co.kr/SITE/data/html_dir/2000/06/09/2000060900

Williams, D. (2002, July). Structure and competition in the U.S. home video game industry. Paper presented at the International Communication Association Conference. Seoul, South Korea.

Wright, J. C., Vandewater, A. C., Bickham, E. A., Scantlin, D. S., Kotler, R. M., Gilman, J. A., et al. (2001). American children's use of electronic media in 1997: A national survey. Applied Developmental Psychology, 22, 31-47.

Yang, S.-J. (2001a). Pre-game event draws strong attention. The Korean Herald. Retrieved September 10, 2002, from http:/ /www.koreaherald.co.kr/SITE/data/html_dir/2001/07/02/200107020005.asp

Yang, S.-J. (2001b). First world cyber games finals open in Seoul. The Korean Herald. Retrieved December 15, 2001, from http:/ /www.koreaherald.co.kr/SITE/data/html_dir/2001/12/06/200112060007.asp

Yang, S.-J. (2002). 56 percent of Korean use Internet at least once a month. The Korean Herald. Retrieved September 23, 2002, from http:/ / www.koreaherald.co.kr/SITE/data/html_dir/2002/01/16/200201160051.asp

Yeung, I. (2001). Association urges government to support interactive technology. Retrieved October 15, 2001, from http:/ / publish.gio.tw/FCJ/past/01071372.html. 